\title{
Os usos da educação no militantismo ambientalista'
}

\author{
Wilson JoséF erreira de Oliveira*
}

Resumo: Esteartigo examina as condições eas lógicas sociais quefundamentam os usos ea reconversão da formação universitária para o exercício profissional na defesadecausas ambientais. A metodologia utilizada consistiu na real ização de entrevistas biográficas com três gerações distintas de ativistas do Rio G rande do Sul, focalizando suas condições sociais de origem, os significados associados ao uso da formação escolar na militância, as principais modalidades de carreirasmilitantes e ostipos de recursose de vínculos sociais quefundamentam o exercício da militância. A pesquisa demonstrou que o ambientalismo constitui um espaço social de reconversão da formação escolar euniversitária para a atuação profissional em diferentes efferas deatividade, com baseem recursosevínculosestabelecidos pelosativistascom partidos políticos, com organizações ecom movimentos sociais no decorrer de seusitineráriosfamiliar, escolar e profissional.

Palavras-chave: militantismo; educação; atuação profissional; ambientalismo.

The use of education in environmental activism

Abstract: This article examines the social conditions and the logic that bases the uses and reconversion of higher education for professional practice in the defense of environmental causes. Themethodology consisted of biographical interviews with threedifferent generations of activistsfrom Rio G rande do Sul, focusing on their social origin, the meanings associated with the use of academic education in militancy, the main kinds of militant careers, and the types of resources and social ties that ground activists' practices. The research showed that environmentalism is a social space for reconverting school and university education into professional action in different spheres of activity, based on resources and ties established by activists with political parties, organizations and social movementsin thecourse of their familial, schooling and professional routes.

Key words: militancy; education; professional practice; environmentalism.

\footnotetext{
* Professor Adjunto da Universidade Federal de Pelotas (UFPel), Rio Grande do Sul, Brasil. wjfo200।@ig.com.br, mdwbg@pop.com.br

।. Este artigo é uma versão modificada de uma comunicação apresentada no XIII Congresso Brasileiro de Sociologia no Grupo de Trabalho Educação e Sociedade. Agradeço os comentários e sugestões de Maria Alice Nogueira e Márcio da Costa, coordenadores do GT.
} 
Apresentação

As competências técnicas e profissionais adquiridas através da formação universitária têm sido consideradas um dos principais recursos utilizados na defesa de causas ambientais, configurando um novo campo de atuação profissional, que tem se caracterizado pela substituição de um modelo de "militante ativista" pelo "militantismo de expertise" (Ollitrault, 1996; 2001; Sainteny, 1999; Gallet, 2002). Em que pesem as diferenças de abordagens relacionadas à produção internacional (e, mais precisamente, européia e norte-americana), a grande maioria dos trabalhos convergem para esse tipo de caracterização do ambientalismo. Algo semelhante ocorre na literatura nacional, destacando-se a intensificação do processo de profissionalização das organizações ambientalistas (Loureiro; Pacheco, 1995), bem como a concentração dos processos de formulação e implementação de políticas ambientais nas mãos de poucos especialistas (Zhouri; Laschefsky; Pereira, 2005; Leite Lopes, 2004). A importância dos recursos escolares e da legitimidade de expertise nas mobilizações coletivas pode ser igualmente observada na defesa dos direitos do homem e de causas humanitárias (Agrikoliansky, 2002; Siméant; D auvin; C.A.H.I.E.R., 2002) e no militantismo sindical (Wagner, 2004), entre outros. Isso está associado, entre outras coisas, à própria dimensão intelectual das práticas políticas e, mais especificamente, à importância do discurso no exercício da política, assim como da complexidade de processos intelectuais envolvidos nos diversos níveis de atividade política (M emmi, 1985; Lagroye, 1993).

Este artigo compreende essa problemática de investigação referente à relação entre engajamento político e escolarização ou, mais precisamente, à importância e aos efeitos da escolarização sobre o ativismo ambiental e à configuração de um militantismo que tem como base principal "a escola": militantes com elevada formação escolar e cuja intervenção está amplamente respaldada na utilização de recursos escolares e de competências técnicas e profissionais. Tal artigo faz parte de uma investigação anterior sobre a emergência e as redefinições do ativismo ambiental entre 1970-2005 (O liveira, 2005) e de duas investigações ainda em curso: uma, sobre as dinâmicas de fabricação e de utilização de manifestações e protestos públicos na defesa de causas ambientais; outra, sobre os processos de produção da política de expansão do eucalipto no Rio G rande do Sul.

D iferentemente dos trabalhos que aceitam como dada e evidente certa tendência geral de institucionalização e de profissionalização do ambientalismo, uma das alternativas abertas pela análise das modalidades de atuação profissional na defesa de causas consiste justamente em considerar os usos da formação escolar como resultado de "investimentos sociais múltiplos" e da participação 
anterior ou simultânea dos atores em um conjunto diversificado de "atividades sociais" (Collovald et al., 2002; Coradini, 2002; Siméant; D auvin, 2002). Em consonância com isso, trata-se de examinar a formação universitária e o exercício profissional não apenas em sua dimensão formal, mas, principalmente, como um espaço de articulação de recursos diversificados para atuação em diferentes esferas de atividade. Sendo assim, este artigo examina as condições e as lógicas sociais que respaldam os usos e a reconversão da formação escolar e universitária em competências profissionais na defesa de causas ambientais, focalizando as concepções de sociedade e de política que fundamentam as definições da atividade profissional, assim como os recursos e os vínculos sociais e políticos associados ao seu exercício.

Para dar conta disso, levanta-se a hipótese de que a expansão do ambientalismo ocorrida a partir da década de 1970 constitui um marco importante do processo de configuração do ambientalismo como um espaço de ampliação das esferas de atuação profissional dos ativistas, ao dar acesso a recursos e a vínculos que poderão ser largamente utilizados para o ingresso e a ocupação de posições técnicas e profissionais em diversos setores de atividade. Isso está associado à utilização instrumental da formação universitária e profissional para a politização de esferas sociais diversificadas, com base em disposições, em concepções e em recursos constituídos no âmbito de diferentes tipos de social ização, e através da inserção simultânea dos ativistas em diversas redes de organizações e de "movimentos sociais" (Oliveira, 2005; 2008).

Para melhor evidenciar isso, o texto está organizado em duas partes principais. Em primeiro lugar, trata-se de demonstrar que os usos da educação no ambientalismo estão fundados em concepções militantistas da formação universitária e de sua relação com o engajamento político. Tais concepções resultam da própria dinâmica de configuração do espaço escolar no Brasil, constituindo um dos ingredientes principais do processo de expansão do ensino superior e da respectiva diversificação das formas de utilização instrumental da formação universitária para a politização e atuação profissional em diferentes esferas de atividade. $\mathrm{N}$ um segundo momento, com base no exame das trajetórias sociais e dos itinerários escolares, militantes e ocupacionais de indivíduos que atuam na defesa de causas ambientais, analisam-se as relações entre os significados e as modalidades de uso da formação escolar e as diversidades de esferas e de redes sociais que contribuem para a aquisição e a reconversão dos recursos sociais que fundamentam tal forma de utilização da escolarização.

0 material utilizado como fonte de dados consiste, basicamente, de informações decorrentes de 60 entrevistas com ativistas que ingressaram no ambientalismo em diferentes momentos do período 1970-2007, possibilitando a caracterização e a comparação de distintas gerações militantes. Trata-se de 
ativistas que atuam em diversos setores de atividade: em partidos políticos, na administração pública e na burocracia estatal, em assessoria e consultoria na "área de meio ambiente", em universidades e centros de pesquisa, no interior da "profissão" em assuntos vinculados ao exercício de determinadas categorias profissionais (jornalismo, direito, biologia, etc.) e no desempenho de funções remuneradas como funcionários e técnicos de $0 \mathrm{NGs}$. Os procedimentos metodológicos utilizados concentraram-se na investigação das trajetórias familiares, escolares, ocupacionais e militantes que os conduziram ao ambientalismo; no exame dos significados e das modalidades de uso da formação escolar associados a essas diversas formas de atuação; e na análise da diversidade de esferas e de redes sociais que contribuem para a aquisição e a reconversão dos recursos que fundamentam suas concepções e suas práticas militantes. 0 material obtido através de tais procedimentos possibilitou a identificação de diferentes padrões de carreiras militantes que conduzem à atuação na "área do meio ambiente" no período considerado.

Formação escolar, engajamento político e militantismo na defesa de causas ambientais

As discussões sobre a importância e a utilidade da "escola" e da formação universitária são temas bastante freqüentes no universo da militância ambientalista. Tais temas não se fazem presentes apenas nas entrevistas, podendo-se observá-los também em mesas-redondas, oficinas e seminários sobre temáticas ambientais, nas reuniões das associações, bem como em conversas rotineiras, brincadeiras e confraternizações entre militantes. N essas situações, os militantes ambientalistas geralmente apresentam a "escola" de forma negativa, no sentido de que a formação escolar e universitária é al go que pouco contribuiu para sua atuação e seu exercício profissional. E os motivos que alegam para isso são bastante variados: sua falta de utilidade prática, a escola pouco lhes deu, eles tiveram que descobrir quase tudo sozinhos, os conhecimentos que utilizam foram sempre adquiridos fora da escola, etc. N o entanto, essa visão negativa que eles apresentam da formação escolar e universitária não resulta de um processo de exclusão ou de falta de acesso à formação superior. Pelo contrário, quando se observa a composição escolar dos dirigentes, o que se constata é que 0 peso quantitativo dos que possuem diplomas de cursos universitários é muito alto. A grande maioria deles tem curso superior completo e uma parte significativa desenvolveu estudos de pós-graduação em nível de especialização, de mestrado e, alguns, de doutorado.

N o entanto, não se deve, a partir disso, estabelecer uma relação direta entre essa forte incidência de militantes com formação universitária e a constituição 
de um militantismo caracterizado pela imposição de competências escolares e de expertise. Q uanto a isso, cabe destacar que os significados e as concepções atribuídas à formação escolar e universitária estão fortemente associados ao engajamento político e aos respectivos recursos e vínculos adquiridos no âmbito da militância. N esse sentido, observa-se que uma das características decisivas nesse tipo de militantismo é a forte ligação entre o começo do engajamento na proteção ambiental e o momento inicial do itinerário universitário e profissional dos militantes. 0 levantamento de informações sobre a idade de entrada em organizações ambientalistas mostrou que a grande maioria dos que atuam no ambientalismo ingressou nesse tipo de militantismo muito antes dos 30 anos, período que corresponde ao tempo de formação e de ingresso no mercado profissional. A emergência do seu engajamento ocorre freqüentemente durante a "juventude", num momento de escolha e de formação profissional; ou, mais precisamente, entre o momento de conclusão do segundo grau e o tempo de entrada na faculdade e 0 desenvolvimento da formação universitária (O liveira, 2007), e não durante um período de maior "disponibilidade", gerada pelo distanciamento em relação às suas funções e atividades profissionais em decorrência da proximidade do período de aposentadoria, como ocorre em outros tipos de militantismo (Agrikoliansky, 2002; Passy, 1998).

Além disso, essa estreita ligação da formação universitária com o engajamento político não ocorre apenas com a entrada no ambientalismo. Pelo contrário, a participação em diversos tipos de organizações e "movimentos sociais", antes mesmo de entrar no ambientalismo, é muito grande entre os entrevistados. São raros os casos daqueles que aderiram ao ambientalismo sem experiências anteriores em organizações políticas as mais diversas, tais como organizações estudantis (grêmios, centros e diretórios acadêmicos), sindicatos, partidos políticos, organizações religiosas e assistenciais, etc. D esse modo, pode-se perceber que, em geral, entre a socialização política no meio familiar e a adesão a organizações ambientalistas encontra-se um conjunto muito diversificado de participações, de desligamentos e de novas adesões a outros tipos de organizações e "movimentos sociais". N esse sentido, pode-se dizer que, em matéria de experiências políticas, os ambientalistas raramente chegam "verdes" na defesa ambiental, como muito bem enunciou um dos entrevistados. Por outro lado, no que diz respeito ao tempo de permanência em organizações ambientalistas, observa-se ainda que tal militantismo tem um tempo de duração relativamente longo. M esmo que se caracterize como algo que ocorre na "juventude", a participação na defesa de causas ambientais é uma característica constante também no período de exercício profissional e não deve ser reduzida a uma "fase" passageira que ocorre apenas no período inicial de seu itinerário escolar e profissional. Q uanto a isso, vale mencionar que, em quase todos os casos conside- 
rados sua "pós-graduação", os cursos realizados ou direcionamento do exercício profissional estão voltados para a "área de meio ambiente".

Esse itinerário universitário e profissional fortemente articulado com 0 engajamento político constitui um dos aspectos fundamentais para a compreensão do significado e da utilidade da formação escolar para os ativistas. Isso porque, para os próprios militantes, muito mais do que a titulação em si, o valor da formação escolar e universitária para o exercício profissional sempre implicam a capacidade ou a competência de "articular" os recursos adquiridos durante o processo de escolarização à "realidade" e à "prática" política. N esse sentido, a aquisição de uma formação universitária, de competências técnicas e de suas vinculações com o exercício profissional; é apresentada pelos próprios militantes como indissociável da capacidade de integrar tais tipos de conhecimentos a "ideologias e práticas políticas"; de modo que, sem esse "compromisso" ou "articulação" com a "realidade", a escola e a formação que ela oferece não têm nenhum valor. Assim sendo, o gosto pelo "social" e pelo engajamento político não resulta de um fracasso escolar e profissional ou do retraimento das atividades ocupacionais. Pelo contrário, a militância e a ocupação de postos em organizações e "movimentos sociais" no decorrer de seu percurso universitário são concebidas como um aspecto "necessário" da formação e do exercício de qualquer tipo de atividade profissional.

D aí, no segundo ano, maispro final, duascolegasminhasentraram no movimento estudantil [...] D aí, foi superlegal porqueeu conse gui enxergar a faculdade... Bah, pra mim, foi tudo o centro acadê mico. Foi oquesalvou a minha faculdade, senão teria sido um horror. Porquedaí eu consegui, sabe, acompanhar a faculdadebem diferente A minha atuação foi bem diferente... Consegui entender o quese passava ali. Foi atravésdo movimento (Entrevista).

Aí o queaconteceu? Eu passei a mai or partedo tempona U nisnos [U niversidadedo Rio dosSinos] com a bolsa, [...] Bom! Foi o meu período inerteda vida. 0 negócio era só estudar. W: N em partido? $\mathrm{N}$ ada! Zero! $\mathrm{N}$ em um movimento social. [...] U m baita dum alienado, um cara totalmentefora dasquestões(Entrevista).

D essa forma, em contraponto às limitações encontradas na "escola formal", eles salientam a grande importância que adquiriu em seus itinerários escolares e profissionais um conjunto diversificado de "vivências", de formas de "sociabilidade", de engajamentos e de militâncias. De maneira geral, eles expressam que foi "fora da escola" e da "universidade" que se estabeleceram o valor e a utilidade de sua formação profissional. Sem o contato e a inserção na "realidade" e na "prática", os conhecimentos adquiridos através da formação escolar e universitária perdem toda sua utilidade. $\mathrm{N}$ esse sentido, as definições que res- 
paldam a atuação na defesa do meio ambiente remetem-nos para concepções militantistas da formação e do exercício profissional, no sentido de que esta é constituída, acima de tudo, pela capacidade de submeter a formação escolar e universitária ao engajamento e à participação política em diversos tipos de organizações e de "movimentos sociais".

Por isso, independentemente do tipo de formação universitária adquirida, é o militantismo em relação à escolarização e à atividade profissional que constitui a tônica principal do relato dos entrevistados e que delimita as perspectivas de inserção e de ocupação de postos no mercado profissional. Antes mesmo de ingressarem no mercado de trabalho, tais indivíduos já dispõem de um conjunto de inclinações, de saberes e de formas de percepção e de ação referentes ao papel da formação escolar para a "prática" profissional; ou, mais precisamente, de disposições a fazer do seu exercício um resultado direto da possibilidade de sua utilização instrumental para a politização de diferentes esferas de atividade. É com base num itinerário familiar, escolar e profissional de intensa participação em diversos tipos de organizações e movimentos sociais que se constitui e são reforçadas essas disposições militantistas da formação escolar e universitária que fundamentam a concepção de que o engajamento é uma forma de extensão ou prolongamento "natural" de sua formação escolar e profissional. Esta extensão deve ser caracterizada, nas palavras dos próprios entrevistados, como uma "área de atuação profissional" enão como uma atividade "externa" ao desempenho de suas ocupações profissionais. Associado a isso, observa-se que o significado e a utilidade da escolarização se definem pela sua instrumentalidade para a "politização" das mais diferentes esferas de atividade, de modo que a participação na defesa do meio ambiente constitui uma das formas de "articulação" da formação escolar e universitária com a militância política para a atuação profissional em partidos políticos, em universidades, em agências governamentais, em empresas de consultoria, em associações, etc.

O s princípios que fundamentam essas concepções e práticas não parecem próprios ou exclusivos desse tipo de atuação profissional. Eles estão vinculados à própria configuração do espaço escolar e do exercício profissional no Brasil (Petrarca, 2007; Connif, 2006; Love; Barickman, 2006; D ezalay; Garth, 2002). Por um lado, são concepções e práticas que fazem do engajamento e da participação política uma forma de extrapolar os "limites de sua profissão" e de associar sua formação escolar e o exercício profissional à "cultura geral" e ao "humanismo" (Coradini, 1998) e, assim, "elevar-se acima do simples exercício de sua profissão" (D ezalay; Garth, 2002). E, por outro, constituem também um dos ingredientes principais das mais diferentes formas de militantismo (C oradini, 2002). Trata-se, enfim, de uma situação em que o sentido e o valor da "profissão" são inseparáveis do "compromisso" com uma "realidade" que é 
"totalmente política" (Pécaut, 1990), de modo que a formação escolar e o exercício profissional requerem a capacidade ou competência de "comprometimento" da formação escolar e técnica com "a realidade" e com a "prática"; ou, no caso, com a "natureza" e com a "vida". N esse sentido, pode-se dizer que a atuação no ambientalismo representa, para os próprios ativistas, uma forma de "ruptura" com o "simples" exercício profissional e de reativação de disposições que possibilitem "extrapolar os limites da profissão".

Em que pese a continuidade dos princípios que respaldam tal atuação, essa maior predominância do ingresso no ambientalismo em plena fase de formação universitária e profissional está vinculada também ao surgimento de novas modalidades de articulação da formação escolar com o engajamento político em diversas esferas de atividade, decorrentes tanto do processo de expansão da escolarização no Brasil quanto de sua correspondência com uma grande proliferação de organizações e "movimentos sociais" vinculados às mobilizações pela "democratização" (O liveira, 2008). Em conformidade com isso, a adesão a organizações e a mobilizações vinculadas à defesa de causas ambientais a partir desse período resultou na configuração da defesa do meio ambiente como um militantismo de reconversão de diferentes tipos de formação escolar e universitária para a atuação profissional em diversas esferas de atividade: estatal, partidária, associativa, acadêmica, religiosa, etc. Atualmente, a inserção anterior e simultânea em diversas redes de organizações e de "movimentos sociais" constitui um dos condicionantes principais da reconversão da formação escolar para o ingresso, a permanência e a ocupação de postos nas organizações e nas instâncias que atuam na defesa de causas ambientais. Ela resulta de processos de socialização política no âmbito familiar e no escolar, da participação anterior em organizações e "movimentos sociais" os mais diversos (estudantis, sindicais, partidárias, religiosas, entre outras), estando também relacionada a trajetos sociais, políticos e profissionais diferenciados.

Dentre os fatores que propiciaram isso, destacam-se, em primeiro lugar, certas mudanças nos contextos político e ideológico dos anos 1980. É o caso da abertura dos espaços de participação política decorrente do "processo de redemocratização" que resultou na intensificação do "fenômeno da militância múltipla", de modo que as redes de lideranças de diferentes organizações e movimentos sociais se tornaram extremamente interligadas (M ische, 1997). Em segundo lugar, encontram-se mudanças no espaço da formação escolar e profissional. Trata-se, mais especificamente, da expansão e da diversificação do ensino superior, que propiciou a ampliação dos usos instrumentais da escolarização e da formação profissional com vistas à politização e à articulação de diferentes esferas de atuação, através da inserção e da militância anterior e/ ou simultânea em diversos tipos de organizações e movimentos sociais (C oradini, 
2002). Por fim, destacam-se certas transformações das próprias bases sociais e das dinâmicas de ingresso no militantismo ambientalista. D esse modo, observa-se que nos anos 1980 há uma mutação de um militantismo composto por lideranças com origens sociais elevadas e cujas intervenções estavam fundadas na bagagem cultural e política herdada ou construída a partir da família de origem, para padrões de atuação que resultam do ingresso de indivíduos com origens sociais mais baixas e heterogêneas, cuja principal base de recursos são os vínculos estabelecidos no decorrer de seus itinerários familiar, escolar e profissional, com partidos políticos, organizações e movimentos sociais diversificados (Oliveira, 2008).

Recursos sociais, carreiras militantes e atuação profissional na "área de meio ambiente" Um dos procedimentos pertinentes à apreensão dos tipos de recursos e de vínculos que conduzem à atuação profissional no ambientalismo é o exame dos principais padrões de carreiras que conduzem à ocupação de cargos e postos destacados como "ambientalistas" em diferentes esferas sociais. Tal análise possibilita apreender como se articulam disposições e situações vinculadas às diferentes seqüências do processo que conduzem os dirigentes ambientalistas à participação efetiva em organizações de defesa ambiental. Como salienta Agrikoliansky (2002, p. 144), a pertinência da noção de "carreira" na análise do militantismo

éprimeiramentedeconsiderar as ações humanas como processos, isto é, como atividades quese desenvolvem no tempo e possuem uma dinâmica própria, ao invés de considerá-las simplesmente como o reflexo denormas sociais, de papéis edecondicionamentos estruturaisinflexíveis. (grifo do autor).

A utilização da noção de carreira na análise do militantismo procura dar conta, por um lado, das disposições favoráveis à participação política e de suas relações com as desigualdades de condições de origem e os respectivos capitais (sociais, econômicos, políticos e culturais) possuídos pelos diferentes agentes sociais (Bourdieu, 1979); e, por outro, dos pertencimentos múltiplos dos atores sociais e dos diversos contextos e das situações relacionadas aos processos de socialização que resultam na constituição e na modificação das disposições que conduzem à participação em mobilizações coletivas (Fillieule, 2001).

Trata-se, portanto, de integrar a perspectiva diacrônica na investigação dos processos de socialização e dos padrões de entrelaçamento de diferentes "ordens de experiência" (familiares, escolares, militantes e profissionais) vinculadas a esse tipo de atuação. D essa forma, tal análise contribui para a compreensão das retribuições alcançadas através do militantismo ambientalista como resultado de "investimentos sociais múltiplos" e da participação anterior ou 
simultânea dos atores em um conjunto diversificado de "atividades sociais". I sso permite apreender as disposições associadas à atuação individual como conseqüência da intersecção entre os processos de socialização vinculados às suas condições de origem e às traj etórias familiares e os que decorrem das experiências e dos diversos contextos interacionais interligados à biografia individual; ou, mais precisamente, à multiplicidade de esferas e de redes sociais associadas ao seu engajamento e à sua participação anterior ou simultânea em um conjunto diversificado de atividades sociais.

D essa maneira, a caracterização dos principais padrões de carreiras que conduzem à ocupação de posições dirigentes em defesa do meio ambiente, a partir dos anos 1970, possibilitou evidenciar a diversificação das modalidades de utilização instrumental da formação escolar para a politização de diferentes esferas de atividade e suas relações com disposições e recursos acumulados através de vínculos estabelecidos em diversos espaços sociais no decorrer dos percursos biográficos dos atores (O liveira, 2008). Assim, tomando como ponto de partida os anos 1970, podem-se distinguir dois padrões principais de reconversão profissional através da militância no ambientalismo para a ocupação de posições de destaque em outras esferas sociais: de um lado, aqueles que tiveram início nos anos 1970 e que se caracterizam pelo uso de recursos e vínculos decorrentes da família de origem; do outro, os que tiveram início nos anos 1980, nos quais as dinâmicas de reconversão profissional estão fundadas nos vínculos estabelecidos a partir do intenso militantismo em organizações estudantis, partidárias e movimentos sociais diversificados. Em meio à grande variedade de padrões de reconversão da formação escolar em competências profissionais, tais exemplos permitem ilustrar certas características principais das modificações ocorridas quanto aos tipos de retribuições obtidas através de tal militantismo².

Como representante dos padrões de carreiras de ambientalistas que se caracterizam pela existência de itinerários cuja reconversão da formação escolar contou com recursos e vínculos estabelecidos, basicamente, através da família de origem, pode-se destacar o caso da atual presidenta da Fundação Gaia. Ela é filha do primeiro presidente da Agapan, o qual teve uma participação destacada na emergência do ambientalismo brasileiro (O liveira, 2008). 0 seu itinerário na defesa ambiental está diretamente articulado às redes de relações construídas a partir da atuação profissional de seu pai. N esse sentido, seu contato inicial com organizações e dirigentes que participavam da defesa do meio ambiente ocorreu na infância, no próprio meio familiar, pois sua casa estava

2. Para uma descrição detalhada das diversas modalidades e dos padrões intermediários de carreiras de ambientalistas que se situam entre esses dois extremos, ver Oliveira (2005; 2008). 
sempre repleta de militantes ambientalistas em decorrência da atuação de seu pai. Ali também aconteciam reuniões e conversas informais com os dirigentes das principais organizações ambientalistas do Rio Grande do Sul e até mesmo de outras regiões do país. Em decorrência disso, seu itinerário universitário e profissional sempre esteve associado à atuação de seu pai: assim que concluiu 0 segundo grau e ingressou na faculdade, começou a acompanhá-lo nas suas viagens internacionais, atuando como secretária dele durante todo o seu percurso na universidade. Em função disso, levou seis anos para concluir o curso de licenciatura em biologia, pois sua intensa militância não possibilitava 0 acompanhamento das aulas, tornando-se, segundo ela mesma, uma espécie de visitante na faculdade. D esse modo, afirma que foram poucas as coisas que aprendeu através de sua formação universitária e conclui: Aprendi muito mais com meu pai, não tenha dúvida.

0 mesmo ocorreu com seu itinerário profissional, uma vez que foi através das relações estabelecidas por seu pai com organizações ambientalistas internacionais, quando ela ainda estava cursando biologia na universidade, que conseguiu um estágio numa "O N G da Alemanha", em função de têlo acompanhado num tour de palestras que ele fez na Europa. N o final do curso de biologia, começou a trabalhar integralmente na organização fundada e presidida pelo pai, passando a supervisionar e a coordenar todos os diferentes projetos e trabaIhos dentro da Fundação Gaia e assumindo, um pouco antes de ele falecer, a posição de presidenta da referida fundação. D essa carreira militante e profissional diretamente vinculada à atuação do pai, tanto no âmbito local como nacional e internacional, resultou uma forte articulação do trabalho desenvolvido pela organização com a esfera internacional. Tal itinerário conduz à concepção da atuação profissional como diretamente associada com questões éticas e filosóficas, estando respaldada em princípios que fazem da atuação profissional algo diretamente subordinado à bagagem cultural, ao conjunto de experiências e aos valores éticos que isso suscita. Assim, salienta que a formação escolar e universitária não é algo que considere fundamental para a atuação na defesa do meio ambiente. M esmo se tratando de sua área, uma vez que, segundo ela, 0 biólogo é naturalmente o profissional que mais tem a ver com ecologia, que mais se aprofunda na questão da ecologia dentre as diversas áreas profissionais, a formação escolar não é uma condição necessária ou fundamental. Antes dela, coloca-se a educação adquirida através do berço familiar, das diferentes experiências que tu passaste na vida e das crenças que tu vais acumulando nesse processo.

$\mathrm{N}$ um outro extremo, encontram-se os padrões de carreira profissional que têm, como principal base de recursos, os vínculos estabelecidos com organizações estudantis, com partidos políticos e com movimentos sociais diversificados. Um dos casos que exemplifica muito bem isso é o da principal liderança 
do Centro de Estudos Ambientais (CEA), um jovem também conhecido como "advogado ambientalista", cuja atuação na "área de meio ambiente" resulta da intersecção entre o contato com a política partidária no meio familiar, uma trajetória social descendente, e o intenso militantismo estudantil e partidário durante a formação secundária e universitária. Ele é filho de um advogado casado com uma integrante de uma família tradicional de Rio Grande, e atuou também como professor de português num colégio público estadual, como membro da direção da O rganização dos Advogados do Brasil (OAB) em Rio $\mathrm{G}$ rande e da Aliança Renovadora $\mathrm{N}$ acional (Arena), na qual tinha muitos amigos. Em que pese 0 engajamento político no meio familiar, não foi com base nos vínculos estabelecidos a partir da família de origem que ele ingressou em organizações políticas e partidárias. Em parte, porque sua relação com a família de origem foi marcada pelo conflito entre seu interesse em fazer "oceanologia" e a decisão do seu pai de que deveria seguir a área do direito. Assim, seu engajamento político ocorreu, primeiramente, durante o segundo grau, quando participou de grêmios estudantis, tornando-se membro da diretoria do centro cívico do colégio, e, principalmente, através de um intenso militantismo durante toda sua formação universitária em diferentes tipos de organizações e movimentos sociais: do M ovimento das Diretas Já, do centro acadêmico do curso de direito e de protestos e manifestações do PT na cidade. Foi com base nesse militantismo que entrou em contato com as lideranças do CEA, que também participavam do PT, e que encontrou, na área do "direito ambiental", uma forma de conciliar seu interesse inicial pela "área do meio ambiente" com suas experiências simultâneas de militantismo estudantil e partidário. D essa forma, atuou como representante do CEA no Conselho $\mathrm{N}$ acional do $\mathrm{M}$ eio Ambiente (C onama), depois como assessor da bancada do PT na Câmara de Vereadores de Pelotas, na área de meio ambiente e de saneamento, e também como assessor jurídico e coordenador da bancada, desenvolvendo ainda uma carreira de ocupação de vários cargos na administração pública: como coordenador do Programa M ar de Dentro durante a "administração petista" no Governo do Rio Grande do Sul, como responsável pela pasta da Secretaria de Planejamento U rbano da Prefeitura M unicipal de Pelotas e como Supervisor de M eio Ambiente da Secretaria M unicipal de M eio Ambiente (Smam) de Porto Alegre nas administrações do PT. Tais atuações foram sempre acompanhadas pela participação simultânea no M ovimento Ecológico Gaúcho. Ao mesmo tempo, investiu na "academia", fazendo um curso de Pós-Graduação em Ecologia H umana na U niversidade Federal do Vale dos Sinos (Unisinos) e outro de Ciência Política no Instituto de Sociologia e Política da Universidade Federal de Pelotas (U fpel). Com base nessa vinculação do direito com a ecologia e com a ciência política passou a ministrar vários cursos de extensão sobre "direito 
ambiental" e conseguiu um emprego para ministrar aulas no Serviço N acional de Aprendizagem Comercial (Senac) de Porto Alegre, num curso de gestão ambiental, ao mesmo tempo que voltou a atuar como representante do CEA e do MEG no Consema. Esse caso é um bom exemplo de como o militantismo ambientalista constitui uma forma de utilização da formação escolar e universitária para a atuação simultânea nas organizações e nas instâncias vinculadas ao movimento ambiental e à política partidária, bem como para a ocupação de postos na administração pública e no ensino de "direito ambiental". Tal itinerário e padrão de reconversão profissional estão ligados a uma concepção da educação e do exercício profissional como devendo estar sempre associados à política partidária e a outras esferas de militância.

\section{Conclusões}

As relações entre a formação e o título adquirido e a atuação profissional não ocorrem de forma direta e automática. Tais relações são sempre mediadas tanto por condições e processos estruturais e objetivos quanto pelas disposições, pelos recursos e pelas competências adquiridas pelos atores no transcurso de suas trajetórias sociais, escolares e profissionais (Bourdieu, 1979; Bourdieu; Boltanski, 1998). N esse sentido, este trabalho demonstrou que as concepções de sociedade e de política características da configuração do espaço escolar e do exercício profissional no Brasil constituem um dos ingredientes principais das relações estabelecidas entre formação e exercício profissional. Tais concepções estão fundadas em princípios que remetem para a imbricação das modalidades de utilização dos recursos escolares e das competências profissionais com as dinâmicas de participação e do militantismo em organizações e movimentos sociais. A maior diversificação dos padrões de atuação profissional na "área de meio ambiente" não resulta de mudanças ocorridas apenas no mundo do trabalho; um dos fatores que contribuíram consideravelmente para isso, como se pode ver, foi a maior oferta de títulos escolares, associada à continuidade das concepções militantistas da profissão.

M uito antes de ocupar uma função profissional em determinada organização e instância de proteção ambiental, os atores já contam com um conjunto de valores, de definições prévias e de recursos sociais que possibilitam ver em tal tipo de atividade uma forma autêntica de exercício e de realização profissional. 0 exame dos padrões de carreiras que conduzem à atuação profissional no ambientalismo foi uma estratégia analítica que possibilitou apreender como determinadas formas de percepção e de avaliação relativas à atuação profissional na "área de meio ambiente" se constituíram no decorrer do tempo e sob determinadas condições sociais. D esse modo, essa análise nos coloca diante das 
disposições e dos recursos sociais que tornam possível o encontro entre determinada formação e o exercício profissional efetivo. A descrição dos padrões de carreiras de ambiental ista permite dar conta de como as concepções militantistas que fundamentam esse tipo de atuação estão relacionadas às disposições e aos respectivos recursos adquiridos com base em vínculos estabelecidos através da inserção dos atores em diferentes esferas sociais, no decorrer de suas trajetórias sociais e de seus itinerários escolares, militantes, ocupacionais e profissionais. D essa forma, foi possível demonstrar que a atuação profissional na "área de meio ambiente" está respaldada em concepções, recursos e práticas profissionais que resultam da articulação entre posição social, formação universitária e inserção em diversas redes de organizações e "movimentos sociais" no decorrer de seus itinerários escolares e profissionais.

Esses resultados evidenciam a necessidade de considerar a formação universitária e o exercício profissional não apenas em sua dimensão formal e institucional, mas, principalmente, como um espaço de reconversão de recursos diversificados para atuação em diferentes esferas sociais. Por isso, ao invés de reduzir as relações entre formação e atividade profissional a algo mecânico e automático, tratou-se de considerar certas condições e lógicas sociais que conduzem os atores a determinado tipo de ativismo. Assim, ao invés de relações abstratas entre formação profissional e "mercado de trabalho", deparamo-nos com um conjunto de experiências passadas, de percepções, de esquemas de classificação adquiridos sobre o exercício profissional, de recursos acumulados no transcurso de suas trajetórias sociais, etc., os quais estruturam as próprias estratégias de inserção e de realização profissional em determinado setor de atividade. Em decorrência disso, o que para muitos constitui uma oportunidade de "trabalho" e de atividade profissional, para outros não está sequer no leque das possibilidades. $N$ esse sentido, pode-se ver na atuação na "área de meio ambiente" uma forma concreta de exercício profissional que resulta de dinâmicas específicas de reconversão social e política.

\section{Referências bibliográficas}

AGRIKO LIAN SKY, E. La liguefrançaisedesdroitsdel'hommeet du citoyen depuis1945. Paris: L'H armattan, 2002.

BO U RDIEU , P.; BO LTAN SKI, L. 0 diploma eo cargo: relaçõesentreo sistemadeprodução e o sistema de reprodução. In: CATAN I, A. e N O GU EIRA, M . A. (O rg). PierreBourdieu: escritos da educação. Petrópolis: Vozes, 1998. p. 127-144.

BO U RD IEU, P. La distinction. Critiquesocialedu jugement. Paris: M inuit, 1979.

CO LLOVALD, A. et. al (D ir.). L 'humanitaireou lemanagement desdévouements. Enquêtesur un militantismede "solidaritéinternationale" em faveur dur tiers-monde. Rennes: PU R, 2002. 
CO N N IFF, M . L. A elitenacional. In: HEIN Z, F. M . Por outra história daselites. São Paulo: FGV, 2006. p. 99-121.

CORADIN I, O . L. Panteões, iconoclastas eas ciências sociais. In: FELIX, L. O .; ELM IR, C. (O rg.) M itos eheróis. construção de imaginários. Porto Alegre: Ed. U niversidade/U FRGS, 1998. p. 209-235.

CO RAD IN I , O . L. Escolarização, militantismo emecanismos de "participação" política. In: H ERED IA, B., TEIXEIRA, C., BARREIRA, I. (O rg.). Comosefazem elè çôesno Brasil. Rio de Janeiro: Relume-D umará, 2002. p. 103-153.

DEZALAY, Y.; GARTH , B. La mondialisation des guerres de palais. La restructuration du pouvoir d'état en Amérique Latine, entrenotables du droit et "C hicago Boys". Paris: Seuil, 2002.

FILLIEU LE, O Propositions pour uneanalyseprocessuelledel'engagement individuel. Revue FrancaisedeSciencePolitique. Paris, v. 51, n. 1-2, p. 199-215, 2001.

GALLET, G . L' expertise, outil del'activismeenvironnemental chez green peace France. In.: H AM M AN , P.; M ÉON , J-M .; VERRIER, B. D iscourssavants, discoursmilitants mélange des genres. Paris: L'H armattan, 2002. p. 109-128.

LAGROYE, J. Sociologiepolitique. Paris: D alloz, 1993.

LEITE LO PES, J. S. A ambientalização dos conflitos sociais, participação econtrolepúblico da poluição industrial. Rio de aneiro: Relume-D umará, 2004.

LO UREIRO , M . R.; PACH ECO , R. S. Formação e consolidação do campo ambiental no Brasil: consensose disputas (1972-1992). Revista deAdministração Pública. Rio deJaneiro, v. 29, n. 4, p. 137-153, out-dez, 1995.

LOVE, J. L.; BARICKM AN , B. J. Elites regionais. In: H EIN Z, F. M . Por outra história das elites. São Paulo: FG V, 2006. p. 77-97.

M EM M I, D. L'engagement politique. In: GRAW IT Z, M .; LECA, J. Traitédesciencepolitique Paris: PU F, 1985. p. 310-366. v. 3 (L'action politique).

M ISCH E, A. D eestudantesacidadãos. Redes dejovenseparticipação política. Revista Brasilèra deEducação, n. 5 e6, p. 134-150, 1997.

O LIVEIRA, W. J. F. Paixão pela natureza, atuação profissional e participação na defesa de causas ambientaisno Rio Grande do Sul entre 1970 einício dos anos 2000. 2005, 464f. Tese (D outorado em Antropologia Social). Programa de Pós-G raduação em Antropologia Social, UFRGS, Porto Alegre.

O LIVEIRA, W. J. F. Formas precárias deemprego, atuação em 0 N G seinserção profissional. Sociedadeem D ebate, Pelotas, v. 13, p. 141-160, 2007.

O LIVEIRA, W. J. F. G êneseeredefinições do militantismo ambientalista no Brasil. D adosRevista deCiênciasSociais, Rio de Janeiro, v. 51, n. 3, p. 751-777, 2008.

O LLIT RAU LT, S. Les écologistes français, des experts en action. RevueFrancaisedeScience Politique, Paris, v. 51, n. 1-2, p. 105-130, fév-avril, 2001. 
O LLITRAU LT, S. Scienceet militantisme: lestransformationsd'uneéchangecirculaire. Lecas del'ecologiefrançaise. Politix, n. 36, p. 141-162, 1996.

PASSY, F. L'action altruiste. Paris-G enève: D roz, 1998.

PÉCAUT, D . O sintelectuaise a política no Brasil: entre o povo ea nação. São Paulo: Ática, 1990.

PET RARCA, F. R. Conflitos profissionais e usos do título acadêmico para o exercício do jornalismo no Rio G rande do Sul. Teoria \& Sociedade, Belo H orizonte(U FM G), v. 1, p. 94119, 2007.

SAIN TEN Y, G. Logiques d'engagement et logiques de rétribution au sein de l'écologisme français. CahiersInternationaux deSociologie, Paris, v. 106, p. 175-200, 1999.

SIM ÉANT, J., D AU VIN , P. \& C.A.H I.E.R. Letravail humanitaire LesacteursdesO N G, du siegeau terrain. Paris: Presses deSciences Po, 2002.

WAG N ER, A-C. Syndicalistes européens. Les conditions sociales et institutionnelles de I'internationalisation desmilitants syndicaux. Actesdela Rechercheen SciencesSociales, Paris, n. 155, p. 13-34, dec. 2004.

ZH O U RI, A., LASC H EFSKY, K., PEREIRA, D. B. A insustentável leveza da política ambiental - desenvolvimento e conflitos socioambientais. Belo H orizonte: Autêntica, 2005.

Recebido em 31 deoutubro de2008 eaprovado em 06 demarço de2009. 